\title{
Foreword
}

\section{Allan Gibb}

I have had the privilege to be in touch with the Internationalizing Entrepreneurship Education and Training (IntEnt) conference initiative since its inception and have been lucky enough to participate in many of its workshops. Like most small enterprises it arose from slender beginnings, driven by an entrepreneur with the vision, Heinz Klandt. It has gained in conceptual and pragmatic strength, and in numbers, over the years. Most importantly, in my view, it has served to create a wider view of the concept of entrepreneurship education, challenging in some respects the dominant US paradigm. As international interest in entrepreneurship education has grown, so, appropriately, has the dynamic of the contributions.

This volume, selected from the proceedings of the 2003 Conference in Grenoble, marks another distinctive step. The overall theme is one of challenge to the knowledge conventions, the context, the location and pedagogy of entrepreneurship education. Alongside several contributions from distinguished authors in the field, there are relative newcomers with insights to challenge the reader, both empirical and conceptual.

IntEnt has always been driven by the desire to make sense of things to the teacher and policy-maker in the entrepreneurship field. It never has been an empty vessel to be filled with purely academic papers in the traditional research conference single disciplinary mode. It draws from many different conceptual frames and is unafraid to embrace creative pragmatism. This volume is no exception and as such is always stimulating. 
Allan Gibb - 9781847201652

Downloaded from PubFactory at 04/26/2023 $03: 28: 37$ PM via free access 